\title{
HOMOLOGAÇÃO DE SENTENÇAS PENAIS ESTRANGEIRAS NO DIREITO INTERNACIONAL PRIVADO BRASILEIRO
}

\author{
Marcos Vinícius Torres Pereira ${ }^{1}$
}

\begin{abstract}
Resumo:
O presente trabalho visa analisar o reconhecimento e execução de decisões estrangeiras em matéria criminal, através da produção de efeitos de uma decisão prolatada em uma jurisdição estrangeira no Brasil. Considerando as propósitos e esforços da comunidade internacional em apresentar soluções aos conflitos criminais, que hoje tendem a ultrapassar as fronteiras geopolíticas dos Estados, o reconhecimento e execução de decisões penais estrangeiras é assunto relevante para o combate à criminalidade internacional, principalmente no Brasil, e para garantir às vítimas, a reparação pelo mal sofrido.
\end{abstract}

Palavras-chave: direito internacional privado, jurisdição indireta, direito penal, homologação de sentenças estrangeiras, Brasil.

\begin{abstract}
:
This essay aims to analise the recognition and enforcement of foreign decisions on criminal matters, through the effects of a decision rendered in a foreign jurisdiction in Brazil. Considering the aims and efforts of the international community to present solutions to criminal conflicts, which overpass today the geopolitical frontiers of the States, the recognition and enforcement of foreign criminal decisions is a relevant issue to fight international criminality, mostly in Brazil, and to guarantee to the victims the liability and damages related to the suffered injury.
\end{abstract}

Keywords: conflict of laws, indirect jurisdiction, criminal law, recognition of foreign decisions, Brazil.

\section{Introdução}

À margem das divergências conceituais e doutrinárias, partindo-se da definição de Estado ditada por Darci Azambuja como "uma sociedade permanente de homens que habita um território fixo e deteminado e tem um governo independente ${ }^{2}$; consagra-se a idéia de que cada Estado exerce o imperium sobre o seu território. Em termos jurídicos, isto significaria, em termos práticos, cada Estado exerce efetivamente jurisdição sobre todo o seu território e somente sobre este, ainda que se diga que a jurisdição do Estado seja ilimitada.

Entretanto, mesmo considerando a premissa de que as decisões judiciais dos Estados só podem produzir seus efeitos jurídicos nos territórios destes; seja em nome da comitas de $\mathrm{Huber}^{3}$, da segurança jurídica, do respeito à jurisdição estrangeira, da reciprocidade, ou, mais recentemente, em nome da cooperação jurídica; os Estados reconhecem - com algumas reservas -

\footnotetext{
${ }^{1}$ Professor adjunto de Direito Internacional Privado, UFRJ.

${ }^{2}$ AZAMBUJA, Darci. Teoria geral do Estado. Porto alegre, Globo, 1955. p. 47.

${ }^{3}$ Vide HUBER, Ulrich. Conflito de leis. Trad. Seminário de Direito internacional Privado da Faculdade de Direito da PUC-RJ. Rio de Janeiro, PUC-RJ, 1951.
} 
decisões prolatadas em outras jurisdições, executando-as em seu território ${ }^{4}$.

Atentando às especificidades das sentenças penais e dos objetivos da tutela penal, o presente trabalho visa analisar a possibilidade e a utilidade do reconhecimento de sentenças penais estrangeiras e, uma vez sejam estas aqui reconhecidas, sua execução no Brasil. Para ressaltar a importância do tema, basta recordar as lições de Bartholus que, ao tratar da questão do conflito de leis, já discutia problemas de jurisdição e de efeitos extraterritoriais das leis, dando grande atenção, em seus comentários, às questões penais ${ }^{5}$.

\section{Breve Histórico da Homologação de Sentenças Estrangeiras no Brasil}

O chamado fundador do DIPRI Brasileiro, Pimenta Bueno fala, na primeira obra de DIPRI oficialmente publicada no Brasil, do reconhecimento de sentenças estrangeiras no Império Brasileiro, sujeitando-as a determinadas condições, e preleciona que:

"nunca se autoriza a execução da sentença que viole a soberania ou leis territoriais, os interesses da nação como tal, a competências dos tribuanis do país quando exclusiva sobre os nacionais, ou enfim que tenha postergado as formas protetoras, ou os trâmites legítimos ${ }^{6,}$.

Ainda no período imperial, o Decreto n 6.982 de 27/07/1878, relativo à execução das sentenças proferidas em países estrangeiros, condicionava, em seu art. $1^{\circ}$, as sentenças estrangeiras a execução no Império Brasileiro mediante reciprocidade do Estado prolator, e se a decisão fosse passada em julgado, e estivesse autenticada pelo cônsul brasileiro e traduzida por intérprete juramentado.

Luiz Alberto Souza e Silva observa o seguinte a respeito da processualística da homologação:

"O juiz do feito solicitava ao Ministro de Justiça esclarecimentos sobre as possíveis dúvidas do princípio da reciprocidade, conforme o art. $5^{\circ}$ do decreto n. 6.982, de 27 de julho de 1878 , e, na falta da reciprocidade, o governo concedia o exequatur que equivalia ao cumpra-se do poder judiciário, conforme Decreto n. $7.777^{7,}$.

Como observa Haroldo Valladão, já na República, a Lei nº 221 de 20/11/1894 trouxe

\footnotetext{
${ }^{4}$ Vide JATAHY, Vera Maria Barreira. Do conflito de jurisdições: a competência internacional da justiça brasieira. Rio de Janeiro, Forense, 2002.

${ }^{5}$ Vide BARTHOLUS. "Conflito de leis" in Revista Jurídica da Faculdade Nacional de Direito da Universidade do Brasil. vol. 4. Trad. Haroldo Valladão a partir da trad. de Joseph Henry Beale. Rio de Janeiro, Universidade do Brasil (UFRJ), 1938.

${ }^{6}$ BUENO, José Antonio Pimenta. Direito internacional privado e aplicação de seus princípios com referência às leis particulares do Brasil. Rio de Janeiro: J. Villeneuve, 1863.p. 144.

${ }^{7}$ SILVA, Luiz Alberto Souza e. Direito internacional privado: Lei de Introdução ao Código Civil. 2 ed. Rio de Janeiro, Lumen Juris, 2000. p. 57.
} 
novas regras para a homologação e execução de sentenças estrangeiras, "não falando em reciprocidade (...) nem em exequatur do poder executivo, substituindo-os pelo processo judicial, da prévia homologação da sentença, perante o mais alto tribunal, o Supremo tribunal Federal ${ }^{8 \%}$. O Decreto $\mathrm{n}^{\mathbf{o}}$ 3.084, de 1898 (Consolidação das Leis da Justiça Federal) tratou da questão da homologação de sentenças estrangeiras nos artigos 7 a 19, mesclando trechos do Decreto $\mathrm{n}$. 6.982/1878 e do Regimento Interno do Supremo Tribunal Federal ${ }^{9}$.

Com a edição do Código Civil e a adoção da Introdução ao Código Civil de 1917, o artigo 16 da Introdução condicionava a exequibilidade das sentenças estrangeiras no brasil ao preenchimento das condições estabelecidas na lei brasileira, sem contudo indicá-las. O CPC/39 tratava da homologação de sentenças estrangeiras, nos artigos 785-796, e, abordava questões específicas como o reconhecimento e execução de sentenças estrangeiras versando matéria falimentar, por exemplo. Algumas regras do CPC/39, como estas sobre julgados sobre quebras estrangeiras certamente se enraízaram na nossa doutrina e jurisprudência, apesar de não terem sido repetidas no CPC/73 ou em legislação posterior, inclusive por tocarem questão de soberania e de competência exclusiva dos tribunais brasileiros.

Com a substituição da Introdução de 1917 pela Lei de Introduçao ao Código Civl de 1942, no artigo 15 desta, foram enumerados os requisitos formais necessários para o reconhecimento das sentenças estrangeiras.

Cabe registrar que a competência constitucionalmente prevista para um órgão de cúpula do judiciário examinar a homologação de sentença estrangeira no Brasil, foi inicialmente prevista na Constituição de 1934, mantendo-se nas constituições posteriores e na tradição do Direito Constitucional Brasileiro.

A posterior edição do Código de Processo Civil de 1973 não deu muita atenção ao tema, apenas determinando, em seus artigos 483 e 484, a competência para homologação do Supremo Tribunal Federal e remetendo ao seu Regimento Interno, no tocante ao procedimento.

Cabe observar que, mesmo com a Emenda Constitucional n. 45, de 31/12/2004, que transferiu a competência para homologação de sentenças estrangeiras e concessão de exequatur às cartas rogatórias do Supremo Tribunal Federal para o Supeiror Tribunal de Justiça, inicialmente por força da Resolução n 22, de 31/12/2004, do STJ, este tribunal passou a cuidar da homologação, utilizando-se das regras do Regimento Interno do STF. Num segundo momento, com a edição da Resolução n ${ }^{\circ}$ 9, de 09/05/2005, do STJ, este órgão vem realizando as

${ }^{8}$ VALLADÃO, Haroldo. Direito internacional privado. v. 3. Rio de Janeiro, Freitas Bastos, 1978. p. 187.

${ }^{9}$ Idem, ibidem. p. 187. 
homologações de acordo com as regras desta resolução até que advenha a reforma de seu regimento interno.

\section{Requisitos Formais para Homologação de Sentenças Estrangeiras no Brasil}

Como o reconhecimento das sentenças estrangeiras no Brasil se sujeita a juízo de delibação, sem exame do mérito, devem ser atendidos determinados requisitos formais para reconhecimento destas. Estes requisitos formais para a homologação foram elencados no artigo 15 da LICC $^{10}$; posteriormente reiterados no artigo 217 do Regimento Interno do STF e, também de certa forma, repetidos ou atualizados, no artigo $5^{\circ}$ da citada Resolução n. 9/05 do STJ.

Estes requisitos seriam os seguintes:

a) a decisão deve emanar de autoridade competente para tal. Apesar do diploma de 1942 ter utilizado a expressão “juiz competente”, de longa data, já resta pacificada na jurisprudência pátria - conforme bem observa Haroldo Valladão e graças ao empenho deste, que advogou neste sentido na SE 912 (Reino da Dinamarca) - a idéia de que a decisão deve ser dada por autoridade competente, segundo a lei estatal de onde é prolatada, ainda que esta autoridade não seja judiciária. Tanto assim o é, que a norma recente do artigo $5^{\circ}$, I da Resolução n. 9 fala em "autoridade competente";

b) ter transitado em julgado, por medida de segurança jurídica, para não tornar efetivo no Brasil algo de que ainda não se tenha certeza alhures;

c) terem sido as partes envolvidas legalmente citadas ou ter se verificado a revelia, em respeito ao princípio do contraditório;

d) a sentença e todos os documentos que devem acompanhá-la devem estar devidamente traduzidos, registrados conforme a exigência da Lei de Registros Publicos Brasileira e deve-se obter a devida chancela consular da documentação, salvo dispensa legalmente prevista ${ }^{11}$.

\section{Sistemas de Homologação de Sentenças Estrangeiras}

Os sistemas adotados pelos Estados para o reconhecimento de sentenças estangeiras são

\footnotetext{
${ }^{10}$ Vide DINIZ, Maria Helena. Lei de introdução ao código civil interpretada. 12 ed. São Paulo, Saraiva, 2007.

${ }^{11}$ Cabe observar que, obviamente, uma sentença oriunda de Angola, Cabo Verde, Guiné-Bissau, Moçambique, Portugal, São Tomé e Príncipe ou Timor Leste não precisarão ser traduzidas por usarem a mesma língua vernácula, apesar de diferenças estilísticas, já que todos integram a Comunidade dos Países de Língua Portuguesa. Ademais, também é importante registrar que a chancela consular é dispensada para as decisões oriundas de Estados com os quais o Brasil tenha tratado em vigor, no qual se preveja a dispensa de tal exigência.
} 
muito variados. Os povos antigos negavam eficácia às decisões de juízes estangeiros, mas esta hostilidade foi paulatinamente sendo vencida através da reciprocidade praticada por povos de princípios morais e religiosos semelhantes. O incremento das boas relações entre os Estados e a maior confiança entre eles, fez evoluir os sistemas, passando-se do total reexame, com propositura de nova ação ao reexame apenas formal da decisão ${ }^{12}$.

Carlos Maximiliano sintetiza os sistemas de reconhecimento de sentenças estrangeiras nos seguintes: territorialidade absoluta, sentença-prova (serve de base a novo processo), revisão do mérito, delibação (verificação de aspectos formais da sentença) e reciprocidade ${ }^{13}$.

Quanto ao sistema adotado pelo Brasil, a tradição do nosso direito consagra o sistema de delibação - inspirado no modelo do antigo "Codice Civile" italiano -, não condicionado a reciprocidade, já que são examinados apenas requisitos formais da sentença, sem o exame do seu mérito. Este, na prática, é apenas verificado à luz do princípio da ordem pública, do respeito à soberania nacional, e, ainda, teoricamente também ao respeito aos bons costumes, por força do art. 17 da LICC/42.

\section{Classificação das Sentenças Penais}

Basicamente, devido ao objetivo específico na esfera penal de se verificar a culpabilidade ou não do agente, as sentenças penais podem absolver ou condenar o agente em decorrência da conduta delituosa, classificando-se, assim, respectivamente, as sentenças penais em absolutórias ou condenatórias. Sem adentrar questões específicas de Direito Penal, por não constituírem objeto deste trabalho, focaremos nas sentenças penais condenatórias, diferenciando as sentenças penais que condenam a penas restritivas de liberdade das sentenças de matéria penal que culminam em outras medidas, tais como a aplicação de medida de segurança e a efeitos de reparação civil ex delicto.

\section{Possibilidade de Homologação das Sentenças Penais Estrangeiras no Brasil}

Tomando por base que a competência legislativa e judiciária na esfera penal costumam ater-se à territorialidade, e, excepcionalmente, à extraterritorialidade; a produção de efeitos de

\footnotetext{
${ }^{12}$ SILVA, Agustinho Fernandes Dias da. Direito processual internacional. Rio de Janeiro, Vilani Filhos, 1971. pp. 100-101. Vide ainda MORELLI, Gaetano. Derecho procesal civil internacional. Trad. Santiago Sentís Melendo. Buenos Aires, Ediciones Juridicas Europa-América, 1953.

${ }^{13}$ MAXIMILIANO, Carlos. Direito intertemporal. Rio de Janeiro, Freitas Bastos, 1946. p. 379.
} 
uma decisão penal em outro Estado poderia ampliar o escopo de efetividade da decisão prolatada. Sem embargo, a possibilidade de homologação de sentenças penais estrangeiras não é pacífica nas doutrinas estrangeira e brasileira. No Brasil, Rodrigo Otávio manifestava-se contrariamente ao seu reconhecimento, dizendo o seguinte:

Quanto às perdas e danos a que já tenha sido o delinquente condenado no processo crime, pensamos que não podem ser havidos por força da sentença condenatória estrangeira. Se bem que alguns escritores queiram ver nessa parte da condenação um efeito civil que possa ter execução extraterritorial, não vemos como fazer essa distinção nos efeitos de uma mesma sentença, reconhecendo em parte dela força executória extraterritorial que é negada no todo ${ }^{14}$.

Discordamos do ilustre mestre, já que a própria lei penal prevê expressamente a possibilidade de homologação de setenças penais estrangeiras. Ademais, o reconhecimento de uma sentença estrangeira pode ser parcial, com o reconhecimento apenas de parte de seus efeitos, seguindo uma tradição já bem assentada do DIPRI brasileiro quanto à possibilidade de homologação parcial $^{15}$.

Cabe registrar que, em nosso país, ainda que o tema da homologação de sentenças penais não tenha merecido a devida atenão específica da doutrina, mormente dos penalistas, iminentes internacionalistas trataram do tema, como Pimenta Bueno, Espínola e Haroldo Valladão.

O Código de Processo Penal, em sua parte final, estabelece as regras para a homologação de sentenças penais estrangeiras (Artigos 787 a790) e o cumprimento de cartas rogatórias no Brasil (Artigos 783 a 786) ${ }^{16}$. Tais dispositivos se mostram, hoje, obsoletos e, ainda que não expressamente revogados, muito pouco de seus dispositivos encontra eco na prática processual de nossos tribunais, principalmente, de nossas mais altas cortes.

A respeito da homologação de sentenças penais estrangeiras no Brasil, a regra mais expressiva de nossa legislação repressiva se encontra no outrora Artigo $7^{\circ}$ do Código Penal, hoje Artigo $9^{\circ}$, ipsis litteris, ipsis verbis:

Artigo $9^{\circ}$ : A sentença estrangeira, quando a aplicação da lei brasileira produz na espécie as mesmas consequências, pode ser homologada no Brasil para:

I - obrigar o condenado à reparação do dano, a restituição e a outros efeitos civis;

II - sujeitá-lo a medida de segurança;

Parágrafo único. A homologação depende:

a) para os efeitos previstos no inciso I, de pedido da parte interessada;

b) para os outros efeitos, da existência de tratado de extradição com o país cuja

\footnotetext{
${ }^{14}$ OTAVIO, Rodrigo. Direito do estrangeiro no Brasil. Rio de Janeiro, Francisco Alves, 1909. p. 237.

${ }^{15}$ Para tanto, vide vasta jurisprudência do STF, com relação a homologação de sentenças estrangeiras de divórcio, anterior à Lei do Divórcio de 1977, com homologação parcial no Brasil, recorrendo-se à adaptação, para moldar e limitar os efeitos da decisão ao instituto do desquite então vigente no Brasil.

${ }^{16}$ Vide FRANCO, Ary Azevedo. Código de processo penal. vol. III: artigos 503 a 811. 7 ed. Rio de Janeiro, Forense, 1960. pp. 333-340.
} 
autoridade judiciária emanou a sentença, ou, na falta de tratado, de requisição do Ministro da Justiça.

Pela leitura do artigo $9^{\circ}$ do nosso Código Penal, percebe-se que nem todas as sentenças penais estrangeiras seriam objeto de homologação no Brasil. O legislador pátrio limita a homologação a casos em que poderia haver efetivamente interesse em que a decisão viesse a produzir efeitos no Brasil. As sentenças penais condenatórias podem ensejar a aplicação de medida de segurança ou prestar-se à reparação civil de dano resultante da conduta delituosa.

Quando uma conduta delituosa é praticada, há o interesse de a sociedade, representada pelo Estado-juiz, puni-la com o fim atributivo e educativo, mas também há o interesse do(s) particular(es) vítima(s), ofendido(s) ou lesado(s), em obter, pecuniariamente, a reparação do dano sofrido. Neste segundo caso, verifica-se o interesse pessoal do particular em buscar a reparação do dano, daí a possibilidade elencada no inciso I do artigo depender de pedido da parte interessada.

Quanto à hipótese prevista no inciso II do artigo, cabe algumas observações. O dispositivo fala expressamente em medida de segurança, não se referindo a pena. Assim, não caberia falar em homologação de sentença penal estrangeira para cumprimento de pena no Brasil em razão de crime, ainda que a previsão brasileira e a estrangeira fossem idênticas para a espécie. Tampouco caberia a homologação quando se tratasse de contravenção penal, por não ter sido incluída na previsão do citado artigo, e também pelo fato de que a própria Lei das Contravenções Penais restringe sua aplicação às contravenções praticadas no teritório brasileiro, de acordo com seu art. $2^{\circ}$.

A homologação de sentença penal estrangeira para aplicação de medida de segurança no Brasil depende do compromisso entre o Brasil e o Estado prolator da sentença, mediante tratado internacional ou, na falta deste, por requisição do Ministro da Justiça. A primeira possibilidade vai de encontro à postura atual dos Estados, em unir esforços e colaboração para melhor alcançarem os objetivos de repressão e desincentivo à criminalidade, através da cooperação judiciária internacional. A segunda hipótese atenderia a fins políticos e diplomáticos calcados na manutenção de boas relações internacionais com determinados Estados, aos quais o Brasil tenha interesse em atender face a determinado caso concreto, considerando o juízo de valor e o bom senso do governo brasileiro em atender a estas hipóteses específicas.

Entendemos como acertada a restrição da legislação brasileira quanto às duas possibilidades elencadas de homologação de sentenças penais estrangeiras. Caso houvesse a 
possibilidade de homologação de sentenças para cumprimento de pena no Brasil, pensamos que não faria sentido o reconhecimento e execução de uma sentença penal condenatória a pena restritiva de liberdade, em prisão brasileira, se o interesse punitivo caberia a outro Estado. Se este realmente tem interesse na aplicação da sanção, deveria pedir a extradição do agente. Caso se considere a hipótese de o agente ser brasileiro, haveria a impossibilidade da extradição se ele for nato e a possibilidade de extradição do naturalizado apenas se houver praticado crime comum antes da naturalização ou se houver comprovado envolvimento deste no tráfico ilícito de entorpecentes e drogas afins, na forma da lei - havendo para esta última hipótese, ainda, resistência para a concessão da extradição, pela não produção da norma adequada esperada -, nos termos do artigo $5^{\circ}$, inciso LI da Carta Magna.

Deste modo, ainda que o agente for brasileiro e sua extradição for impossibilitada ou dificultada nestes termos, qual seria o interesse do governo brasileiro no reconhecimento e execução de sentença penal condenatória a pena privativa de liberdade, com o cumprimento da pena em instituição no Brasil? Os gastos com a manutenção de um presidiário são altos e isto contribuiria para o aumento da superpopulação carcerária; tornando-se, portanto, a homologação desaconselhável. Em sentido contrário, seria possível defender a homologação com a alegação do interesse no combate à impunidade como um todo, na ordem internacional, e que, por esta razão, não deveria ater-se a fronteiras geopolíticas. Vemos o primeiro argumento como mais lógico e pensamos que não haveria interesse prático para o governo brasileiro na execução deste tipo de setença penal condenatória no Brasil.

Ainda com relação à possibilidade de homologação de sentença criminal estrangeira condenatória a pena privativa de liberdade, mesmo inviabilizada no Brasil, são imprescindíveis duas observações importantes, como relação a duas situações que não se confundiriam com efeitos de sentença penal estrangeira, condenatória a pena privativa de liberdade. Primeiramente, existe a possibilidade de transferência de presos estrangeiros que cumprem pena no Brasil, por crimes aqui cometidos. Isto se dá pela existência de tratados bilaterais entre o Brasil e o país de origem do preso $^{17}$, por razões humanitárias, para que este possa, principalmente, cumprir pena próximo a seus familiares. Importante registrar que este benefício somente será concedido com a

\footnotetext{
${ }^{17} \mathrm{O}$ Brasil atualmente possui tratados para tranferência de pessoas condenadas com os seguintes países: Argentina (celebrado em 11/9/1998, promulgado pelo Decreto n. 3.875, de 23/07/2001), Canadá (celebrado em 15/07/1992, promulgado pelo Decreto n. 2.547, de 14/04/1998), Chile (celebrado em 29/04/1998, promulgado pelo Decreto n. 3.002, de 26/03/1999), Espanha (celebrado em 04/05/1998, promulgado pelo Decreto n. 30/04/1998), Paraguai (celebrado em 29/10/2002, promulgado pelo Decreto n. 4.443, de 28/10/2002), Reino Unido da Grã-Bretanha e da Irlanda do Norte (celebrado em 29/01/2002, promulgado pelo Decreto n. 4.107, de 28/01/2002).
} 
concordância do condenad Em segundo lugar, deve-se ressaltar que a entrega de criminosos internacionais, com a qual o Brasil se compromete no âmbito do Tribunal Penal Internacional $(\mathrm{TPI})^{18}$ não se confunde com a extradição e tampouco se trataria de efeito de uma sentença penal estrangeira, já que o TPI é um tribunal internacional, que, ipso facto, dita sentenças internacionais.

\section{7. Óbices à homologação}

Ainda que uma sentença estrangeira atenda aos requisitos formais para sua homologação no Brasil, devido ao sistema de delibação, o conteúdo da sentença deve "passar por uma espécie de filtro" para produzir efeitos em nosso país. Este filtro se concretiza na tríplice fórmula a ser respeitada: ordem pública, soberania nacional e bons costumes.

Tal fórmula se deve a Clóvis Bevilaqua, pois aparece no artigo 17 da Introdução de 1917 com a seguinte redação: "São reconhecidos, no Brasil, os direitos adquiridos no estrangeiro, em virtude de um ato praticado no estrangeiro, segundo a lei estrangeira, contanto que o exercício não importe ofensa à soberania nacional brasileira, à ordem pública e aos bons costumes".

Com a reforma de 1942, a tríplice fórmula foi repetida no artigo 17 da Lei de Introdução com outra redação que passava a sujeitar a eficácia das "leis, atos e sentenças de outro páis, bem como quaisquer declarações de vontade" a que não ofendessem a soberania nacional, a ordem pública e os bons costumes".

Comungamos com a opinião de Agustinho Fernandes Dias da Silva de que a homologabilidade das sentenças penais estrangeiras estaria condicionada a que a sentença gerasse resultado idêntico à previsão legal brasileira, conforme o caput do artigo $9^{\circ}$ de nosso Código Penal:

As restrições relativas à ofensa à soberania nacional, aos bons costumes ou à ordem pública, são, naturalmente, aplicáveis também às sentenças penais estrangeiras, sendo isso assegurado, aliás, em grande parte, pela exigência de que a lei brasileira produzisse na espécie as mesmas consequências ${ }^{19}$.

A fórmula da Lei de Introdução foi ainda repetida no artigo 216 do Regimento Interno do STF. A Resolução n 9 do STJ parece ter rompido a tradição da tríplice fórmula, ao excluir “os

\footnotetext{
${ }^{18}$ O Brasil, após a adesão em 2000, aprovou o Tratado pelo Decreto Legislativo n. 112, de 06/06/2002, e, o promulgou pelo Decreto Executivo n. 4.388, de 25/09/2002. O TPI se encontra em funcionamento, desde 2002, já tendo julgado várias violações ocorridas no continente africano, com várias condenações.

${ }^{19}$ SILVA, Agustinho Fernandes Dias da., op. cit. p. 167.
} 
bons costumes". Não nos parece que tenha sido prejudicial tal exclusão. Desde a Introdução de 1917, a alegação de “ofensa aos bons costumes" raramente vinha sendo utilizada por nossa jurisprudência, por ser extremamente subjetiva, sendo preferida - mesmo em matéria de Direito de Família, por exemplo, onde os costumes têm grande relevância - a alegação de "ofensa à ordem pública", ainda que esta também seja, muitas vezes, de difícil conceituação ${ }^{20}$. Entretanto, como o referido dispositivo da LICC/42 ainda se encontra em vigor, faz-se mister observar que a maioria da doutrina ainda considera o terceiro óbice - ofensa aos bons costumes - legalmente vigente.

\section{Efeitos da Sentença Penal Estrangeira não Homologada?}

Questão polêmica se refere à possibilidade de produção de efeitos de sentença penal estrangeira condenatória no Brasil que não tenha sido homologada pelo nosso Poder Judiciário o que não seria raro, devido à previsão legal do citado art. $9^{\circ}$ do estatuto penal. Para refletir sobre tal questão, apontamos duas hipóteses - com as quais estamos de acordo -, ressaltadas pela doutrina internacionalisata como passíveis de produção de efeitos do decisum penal estrangeiro no Brasil, a despeito de ter se dado a homologação.

$\mathrm{O}$ art. 63 do Código Penal estabelece que a sentença penal condenatória estrangeira gera efeito de reincidência. Como bem observa Nadia de Araujo, ela seria reexaminada como prova em processo penal em curso no Brasil, acarretando a majoração pela reincidência ${ }^{21}$.

Marcela Harumi destaca ainda a necessidade de se computar em território nacional, para fins de detração, pena eventualmente cumprida no estrangeiro, classificando tal efeito como efeito remoto da sentença estrangeira no Brasil ${ }^{22}$.

\section{Execução das Sentenças Penais Estrangeiras Homologadas no Brasil}

Uma vez homologada pelo STJ, a sentença penal estrangeira será executada pela justiça federal, conforme competência constitucionalmente determinada pelo artigo 109, inciso X da

\footnotetext{
${ }^{20}$ Vide DOLINGER, Jacob. A evolução da ordem pública no direito internacional privado. Rio de Janeiro, s/ed, 1979.

${ }^{21}$ ARAÚJO, Nadia de (coord.). Cooperação jurídica internacional no Superior Tribunal de Justiça: comentários à Resolução no. 9/2005. Rio de Janeiro, Renovar, 2010. p. 37.

${ }^{22}$ HARUMI, Marcela. Dos casos em que é desnecessário homologar uma sentença estrangeira. Tese de doutorado (Prof. Orientadora Carmen Tibúrcio). Rio de Janeiro, UERJ, 2009. pp. 105 e segs
} 
Carta Magna. Tal competência também é reiterada por nossa legislação infraconstitucional. Mantendo tradição no nosso Direito, a execução da sentença homologada pela corte superior cabe ao juiz federal, mais precisamente ao juiz federal da comarca onde haja o interesse na execução da sentença.

\section{Tratados Internacionais e Homologação de Sentenças Penais Estrangeiras no Brasil}

Entre os tratados internacionais ratificados pelo Brasil, cabe examinar aqueles que versam a homologação de sentenças penais estrangeiras, criando para nosso Estado uma obrigação internacional, com determinado contéudo específico, para a produção de efeitos de decisões penais estrangeiras em nossa jurisdição, seguindo uma processualística, por vezes, específica. Assim, a seguir, destacamos o Código Bustamante, por sua importância histórica, enquanto tratado multilateral no continente americano; os tratados bilaterais de cooperação internacional vigentes com a Espanha, a Itália e a França; e o Protocolo de Las Leñas, que regulamenta as principais questões processuais internacionais, entre os Estados-membros do Mercosul.

\subsection{Código Bustamante}

O Códito Bustamante ${ }^{23}$, ainda hoje vigente, mesmo superado em vários pontos pelas convenções interamericanas, realizadas no âmbito das CIDIPs, inclui nas suas regras para a homologação de sentenças estrangeiras, a possibilidade de reconhecimento de decisões penais, no tocante à reparação civil decorrente do delito, no seu Livro IV. O artigo 436 veda expressamente o reconhecimento e execução de sentenças criminais entre os Estados contratantes, ao passo que o artigo 437 excepciona a regra geral, com a possibilidade de reconhecimento para o efeito de reparação civil ex delicto e consequentes efeitos sobre os bens do condenado, desde que haja a "audiência do interessado" e sejam cumpridas as condições processuais estabelecidas no próprio Código.

É curioso observar que o Código Bustamante também inclui no mesmo Livro IV (Direito Processual Internacional) normas para a extradição entre os países signatários ${ }^{24}$, sendo ainda hoje

\footnotetext{
${ }^{23} \mathrm{O}$ chamado Código Bustamante consiste na Convenção Interamericana de Direito Internacional Privado, elaborada, em 1928, por Antonio Sánchez de Bustamante y Sirven, sob a forma de uma codificação de normas de DIPRI, e, foi aprovada pelo Decreto Legislativo n. 5.647, de 08/01/1929, e, promulgada pelo Decreto Executivo n. 18.871, de $13 / 08 / 1929$.

${ }^{24}$ Além do Brasil, também são Estados ratificantes do Código, Bolívia, Chile, Costa Rica, Cuba, El Salvador,
} 
utilizado pelo Brasil, quanto aos pedidos extradicionais requeridos por Estado signatário do Código, que não possua tratado bilateral de extradição vigente com o governo brasileiro. Fato este que poderia ser apontado como um mecanismo substitutivo à impossibilidade de reconhecimento de sentenças penais condenatórias a penas restritivas de liberdade, por viabilizar o julgamento e/ou cumprimento da pena no Estado signatário legitimado à persecutio criminis.

\subsection{Tratados Bilaterais de Cooperação Internacional}

O Convênio de Cooperação Judiciária em Matéria Civil ${ }^{25}$, celebrado com o Reino da Espanha, em 13/04/1989, prevê a cooperação nas áreas cível, comercial, trabalhista e de contencioso administrativo. $\mathrm{O}$ artigo 15, 4, do Convênio amplia este escopo e prevê expressamente a homologação de decisões penais estrangeiras, para os efeitos de reparação do crime.

O Tratado Relativo à Cooperação Judiciária e ao Reconhecimento e Execução de Sentenças em Matéria Civil ${ }^{26}$, celebrado com a República da Itália, em 17/10/1989, também inclui no âmbito de aplicação do tratado, as sentenças penais no tocante à reparação civil ex delicto e à restituição de bens, conforme artigo $1^{\circ}, 3$.

O Acordo de Cooperação Judiciária em Matéria Civil ${ }^{27}$, celebrado com a França, em 28/05/1996, também extende, na mesma linha, a aplicação das normas do tratado para a homologação de sentenças penais versando a reparação civil decorrente do delito, no artigo 17.

\subsection{Protocolo de Las Leñas}

O Protocolo de Las Leñas de Cooperação e Assistência Jurisdicional em Matéria Civil, Comercial, Trabalhista e Administrativa ${ }^{28}$, celebrado em 1992, estabelece normas de Direito Processual Internacional, entre os países do Mercosul, a saber Brasil, Argentina, Paraguai e

Equador, Guatemala, Haiti, Honduras, Nicáragua, Panamá, Peru, República Dominicana e Venezuela.

${ }^{25} \mathrm{O}$ Brasil aprovou o Convênio pelo Decreto Legislativo n. 31, de 16/10/1990, e, o promulgou pelo Decreto Executivo n. 166, de 03/07/1991.

${ }^{26}$ O Brasil aprovou o Tratado pelo Decreto Legislativo n. 78, de 20/11/1992, e, o promulgou pelo Decreto Executivo n. 1.476 , de $02 / 05 / 1995$.

${ }^{27}$ O Brasil aprovou o Acordo pelo Decreto Legislativo n. 163, de 03/08/2000, e, o promulgou pelo Decreto Executivo n. 3.598, de 12/09/2000.

${ }^{28}$ O Brasil aprovou o Tratado pelo Decreto Legislativo n. 55, de 19/04/1995, e, o promulgou pelo Decreto Executivo n. 2.067, de 12/11/1996. 
Uruguai $^{29}$. O grande mérito do Protocolo é facilitar o reconhecimento e execução de decisões judiciais e arbitrais entre os Estados-membros, possibilitando a produção de efeitos das decisões, através de cartas rogatórias, conforme o artigo 19 do Protocolo. O artigo 18, in fine, extende a aplicação do mecanismo de cooperação às "sentenças em matéria de reparação de danos e restituição de bens pronunciadas na esfera penal".

\section{Considerações Finais}

Uma sentença penal estrangeira, assim como as sentenças penais em geral, poderá ser reconhecida pelo STJ de acordo com a processualística prevista para a chamada homologação de sentenças estrangeiras no Brasil. Entretanto, devido às especificidades das sentenças penais estrangeiras, isto não seria possível para qualquer sentença penal estangeira. Por exigência do artigo $9^{\circ}$ do Código Penal, somente na hipótese de homologação para reparação civil ex delicto ou para aplicação de medida de segurança no Brasil caberia o reconhecimento. E desde que atendidas as condições previstas no citado artigo.

Uma vez homologada, seria a sentença executada pela justiça federal, dando efetividade ao comando contido na decisão e prestigiando, assim, o incremento das boas relações entre os Estados e a cooperação jurídica internacional. Ademais, a produção de efeitos, em nosso território, do conteúdo de uma sentença prolatada alhures prestigia e efetiva o acesso à justiça, já que a parte se sentirá satisfeita, atendida, no seu anseio de justiça, a obtenção dos resultados, efeitos da decisão, do conflito devidamente composto, resolvido. Cumprindo-se, assim, um dos direitos inalienáveis do indidvíduo, na seara dos Direitos Humanos, o acesso à justiça, na sua parte final, mas mais efetiva, a produção dos resultados da decisão.

\section{Referências Bibliográficas}

AZAMBUJA, Darci. Teoria geral do Estado. Porto alegre, Globo, 1955. ARAÚJO, Nadia de (coord.). Cooperação jurídica internacional no Superior Tribunal de Justiça: comentários à Resolução no. 9/2005. Rio de Janeiro, Renovar, 2010.

\section{BARTHOLUS. "Conflito de leis" in Revista Jurídica da Faculdade Nacional de Direito da}

\footnotetext{
${ }^{29}$ Apesar da assinatura do Protocolo de Adesão da República Bolivariana da Venezuela ao Mercosul, em Caracas, em 2006; até o presente momento, este Estado não se tornou efetivamente membro deste bloco sul-americano, razão pela qual tampouco utiliza os tratados de DIPRI pertinentes ao bloco.
} 
Universidade do Brasil. vol. 4. Trad. Haroldo Valladão a partir da trad. de Joseph Henry Beale. Rio de Janeiro, Universidade do Brasil (UFRJ), 1938.

BUENO, José Antonio Pimenta. Direito internacional privado e aplicação de seus princípios com

referência às leis particulares do Brasil. Rio de Janeiro: J. Villeneuve, 1863.

CAMPANHOLE, Adriano e CAMPANHOLE, Hilton Lobo. Constituições do Brasil. São Paulo, Atlas, 2000.

DINIZ, Maria Helena. Lei de introdução ao código civil interpretada. 12 ed. São Paulo, Saraiva, 2007.

DOLINGER, Jacob. A evolução da ordem pública no direito internacional privado. Rio de Janeiro, s/ed, 1979.

TIBÚRCIO, Carmen. Vade-Mécum de direito internacional privado: ed. universitária. 2 ed. ed. rev. e atual. Rio de Janeiro, Renovar, 2002.

ESPÍNOLA, Eduardo. Elementos de direito internacional privado. Rio de Janeiro, Jacintho Ribeiro dos Santos, 1925.

- ESPÍNOLA FILHO, Eduardo. A lei de introdução ao código civil brasileiro comentada. 3 vols. Rio de Janeiro, Freitas Bastos, 1944.

FRANCO, Ary Azevedo. Código de processo penal. vol. III: artigos 503 a 811 . 7 ed. Rio de Janeiro, Forense, 1960.

HARUMI, Marcela. Dos casos em que é desnecessário homologar uma sentença estrangeira. Tese de doutorado (Prof. Orientadora Carmen Tibúrcio). Rio de Janeiro, UERJ, 2009.

HUBER, Ulrich. Conflito de leis. Trad. Seminário de Direito internacional Privado da Faculdade de Direito da PUC-RJ. Rio de Janeiro, PUC-RJ, 1951.

JATAHY, Vera Maria Barreira. Do conflito de jurisdições: a competência internacional da justiça

brasieira. Rio de Janeiro, Forense, 2002.

MAXIMILIANO, Carlos. Direito intertemporal. Rio de Janeiro, Freitas Bastos, 1946.

MORELLI, Gaetano. Derecho procesal civil internacional. Trad. Santiago Sentís Melendo. Buenos Aires, Ediciones Juridicas Europa-América, 1953.

OTAVIO, Rodrigo. Direito do estrangeiro no Brasil. Rio de Janeiro, Francisco Alves, 1909.

PIOVESAN, Flávia. Direitos humanos e o direito constitucional internacional. 7 ed. Rio de Janeiro, Saraiva, 2006. 
SILVA, Agustinho Fernandes Dias da. Direito processual internacional. Rio de Janeiro, Vilani Filhos, 1971.

SOUZA NETO, Paulino José Soares. "Da aplicação da Lei Penal" in Anais do $\mathbf{1}^{\circ}$ Congresso Nacional do Ministério Público, São Paulo, 1942.

TIBURCIO, Carmen. Temas de direito internacional. Rio de Janeiro, Renovar, 2006.

VALLADÃO, Haroldo. Direito internacional privado. v. 3. Rio de Janeiro, Freitas Bastos, 1978. 